\title{
"Day-ahead power market behavior for a small supplier: case of Turkish market"
}

\begin{tabular}{|c|c|}
\hline AUTHORS & $\begin{array}{l}\text { Avni Özözen } \\
\text { M. Özgür Kayalica (D https://orcid.org/0000-0001-9828-7385 } \\
\text { R https://publons.com/researcher/1984150/m-ozgur-kayalica/ } \\
\text { Gülgün Kayakutlu (D) https://orcid.org/0000-0001-8548-6377 }\end{array}$ \\
\hline ARTICLE INFO & $\begin{array}{l}\text { Avni Özözen, M. Özgür Kayalica and Gülgün Kayakutlu (2018). Day-ahead } \\
\text { power market behavior for a small supplier: case of Turkish market. } \\
\text { Environmental Economics, 9(2), 70-79. doi:10.21511/ee.09(2).2018.05 }\end{array}$ \\
\hline DOI & http://dx.doi.org/10.21511/ee.09(2).2018.05 \\
\hline RELEASED ON & Friday, 06 July 2018 \\
\hline RECEIVED ON & Sunday, 03 June 2018 \\
\hline ACCEPTED ON & Wednesday, 04 July 2018 \\
\hline LICENSE & $\begin{array}{l}(c) \text { EY-NG } \\
\text { This work is licensed under a Creative Commons Attribution-NonCommercial } 4.0 \\
\text { International License }\end{array}$ \\
\hline JOURNAL & "Environmental Economics" \\
\hline ISSN PRINT & $1998-6041$ \\
\hline ISSN ONLINE & $1998-605 X$ \\
\hline PUBLISHER & LLC "Consulting Publishing Company "Business Perspectives" \\
\hline FOUNDER & LLC "Consulting Publishing Company "Business Perspectives" \\
\hline
\end{tabular}

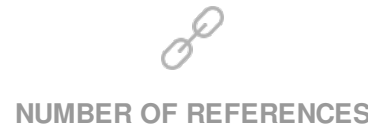

20

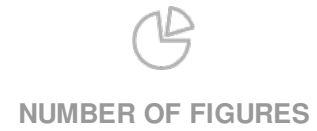

7
NUMBER OF TABLES

5

(C) The author(s) 2023. This publication is an open access article. 


\title{
Avni Özözen (Turkey), M. Özgür Kayalica (Turkey), Gülgün Kayakutlu (Turkey) Day-ahead power market behavior for a small supplier: case of Turkish market
}

\begin{abstract}
The day-ahead power market has become more complex with the allowance of block purchases from private sales companies. Resource handling has become the prominent problem for both energy suppliers and energy distributers. Complexity of the problem forces the approach by each role player in the market. This research handles the market position of a small hydropower plant owner who has negligible effect on market price construction in a complex competition environment. Based on an optimum schedule of three days, this model proposes policies for the power generator to maximize its profits. An MILP model, which uses the day-ahead market price forecasts from a hybrid SARIMA-ANN price forecasting model, is designed to optimize the day-ahead generation schedule. The case application in Turkish power market shows the increase of profit with a reliable generation schedule.
\end{abstract}

Keywords: day-ahead power market, power forecasting, adjusted producer.

JEL Classification: Q41, Q47.

Received on: $3^{\text {rd }}$ of June, 2018.

Accepted on: $4^{\text {th }}$ of July, 2018.

\section{Introduction}

Liberalization of the energy markets has started during the end of eighties and the markets have been through countless changes ever since. While it still goes on particularly in some developing countries, in developed ones, the old conventional power plants are being rapidly decommissioned and replaced by more sustainable generation sources due to the environmental concerns arising especially from the priority in meeting the $\mathrm{CO} 2$ targets. Thanks to the enhancements in new technologies, the levelized cost of electricity for renewables has been decreasing year over year and this puts the renewables into the prominent position to meet the increase in electricity demand. This shift from coal generation to renewables will soon be followed by the developing countries undoubtedly. However, in the meanwhile, introducing aggressive amount of renewable capacities into power markets in a short run brings more regulation complexity, uncertainty and lower prices along with it. While giant companies in power industry manage to survive with their diversified portfolios, smaller investors need to be more sensitive with their natural resources in the market. Limited or no flexibility in renewable generation highlights the importance of efficient and optimal use of the resource with a good planning for a higher chance for survival in a

(c) Avni Özözen, M. Özgür Kayalica, Gülgün Kayakutlu, 2018.

Avni Özözen, Trade manager, Borusan-EnBW Energy, Maslak, Istanbul, Turkey.

M. Özgür Kayalica, Professor, Department of Management Engineering and TEGAM, Macka, Istanbul Technical University, Istanbul,Turkey.

Gülgün Kayakutlu, Professor, Energy Institute, Maslak, Sariyer, Istanbul Technical University, Istanbul, Turkey.

This is an Open Access article, distributed under the terms of the Creative Commons Attribution 4.0 International license which permits unrestricted re-use, distribution, and reproduction in any medium, provided the original work is properly cited. sustainable environment. A hydro power plant with a small size reservoir has negligible impacts on the prices and needs to adapt itself to the market conditions in a sustainable way.

This study is designed with the motivation of analyzing the profit maximizing strategies of the suppliers with less market power. Those suppliers are trying to make money by (i) power generation, (ii) storage and (iii) do-nothing decisions. This paper suggests a model to optimize the stop/store/start decisions based on a market price forecast performed using a new SARIMA-ANN forecasting method to be called hereafter as SANNFORM. The proposed Mixed Integer Linear Programming (MILP) can only be used based on certain assumptions. However, the case study implemented in this work as a small-sized hydroplant has shown that changing the policies on the right time with the good forecasts can maximize the profit for small players.

This paper is organized as follows. The next section is reserved for the brief review of day-ahead market (DAM) research and the current status of the Turkish market. The second section explains the forecasting and optimization methods. The third section implements the case followed by the discussion of the results. Finally, the last section is reserved for conclusion and recommendations.

\section{Literature review}

This section consists of the theoretical background and a review of the literature on the day-ahead power market with particular reference to the Turkish case. Electricity market study of the 21st century has been improved by following Gabriel et al. (2013) and Harris (2013). Those two books have definitely led lots of power market traders in terms of resource optimization and market price 
construction. Although the day-ahead market was studied since 2001 (Contreras et al., 2001), the enhancement of renewable energy markets, regional heating and the construction of smart grids have changed the market analysis, as Marzband et al. (2013) state.

The literature on price forecasting in the power sector is vast and also depends on the market design in the national or supranational power markets. This study prefers to focus on day-ahead pricing and limit its view to day-ahead forecasting only. The research on day-ahead market is focused on three approaches: 1) better price or resource forecasting (Efthymoglou \& Vlachou, 1989; Fazlollahi et al., 2012; Kekatos et al., 2013; Keles et al., 2016; Mandal et al., 2013; Panapakidis \& Dagoumas, 2016; Ziel et al., 2015); 2) uncertainty and risk handling (Gangammanavar et al., 2016; ShayeganRad et al., 2017; Wang et al., 2016; Yan et al., 2017); 3) supply or demand scheduling (Samimi et al., 2015; Zamani et al., 2016; Braun, 2016; Pousinho et al., 2016). This study contributes to the field on scheduling power generation focused on the benefits of a small player.
Day-ahead market is a physical market, where power supply meets power demand. Each day, it is set in order to determine the supply-demand curves for each hour of the following day (day-ahead). Generation companies constitute the supply side, while the retailers associated with the formerly bundled distribution companies (DisCo(s)) and wholesale companies represent the demand side. Furthermore, any legal entity that undertakes delivery obligations for its stakeholders, customers and business channels may participate in the market. The day-ahead electricity market works through bids to buy and offers to sell as in traditional supply and demand principles ${ }^{1}$. Suppliers offer for the quantities they can provide, while demand side players offer for the quantities they ask. At the very point where supply curve intersects demand curve, the aggregated price and the aggregated quantity are settled according to the rule that the price per unit generation should be able to pay at least for the marginal costs of the suppliers to guarantee that they are not worse-off participating in the market (Market Clearing Price). Figure 1 shows a simple day-ahead market mechanism ${ }^{2}$

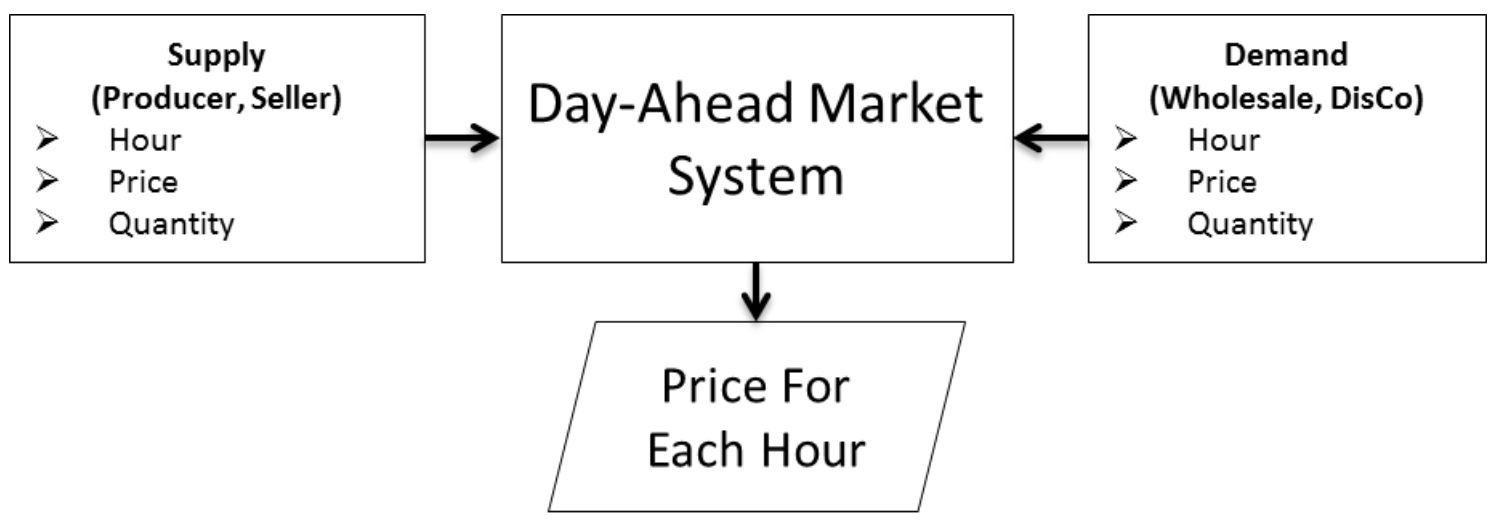

Source: Drawn by the authors.

The merit order (i.e., the ranking of respective marginal costs of generators with different inputs) in the Turkish electricity market consists of all channels of generation, except the nuclear, as can be seen from Figure 2. The lowest-cost producers are must-run (Build Operate-Build Operate Transfer power plants, government-owned Combined Cycle Gas Turbines (CCGTs), EUAS (state-owned "Electricity Generation Company") hydro power plants) generation and Renewable Energy Power Plants (REPPs), of which the lowest-cost generation comes from Wind Energy Power Plants (WEPPs).

\footnotetext{
1 Long-run terms of power trade are set through private bi-lateral agreements amongst buyers and sellers.

${ }^{2}$ Currently, in the Turkish power market, DAM operations (offers and bids) for the following day are taken until 12.00 each day through EPIAS (Energy Market Administrating Authority) portals and the settled prices and quantities are published at 14.00.
}

Renewable energy is followed by Hydro Power Plants (HEPPs) with large capacities, the ones considered as a balancing power unit in the first place, coal power plants, natural gas power plants (in an order regarding relative efficiency levels) and fuel oil, respectively. Where supply meets demand, market clearing price and market clearing quantity are determined. This price is binding for all of the DAM participants for the delivery date and is a value between minimum and maximum levels $(0$ and 500 TL/MWh in Turkey).

Generation units that constitute the supply curve individually have distinguishing and determinant features and capabilities due to the nature of the generation source and the technical properties. The features of different generation units that 
shape the most of the supply curve are roughly given in Table 1 below. Since there are many producers, the individual properties may differ from the general scale.

\section{DAM Merit Order}

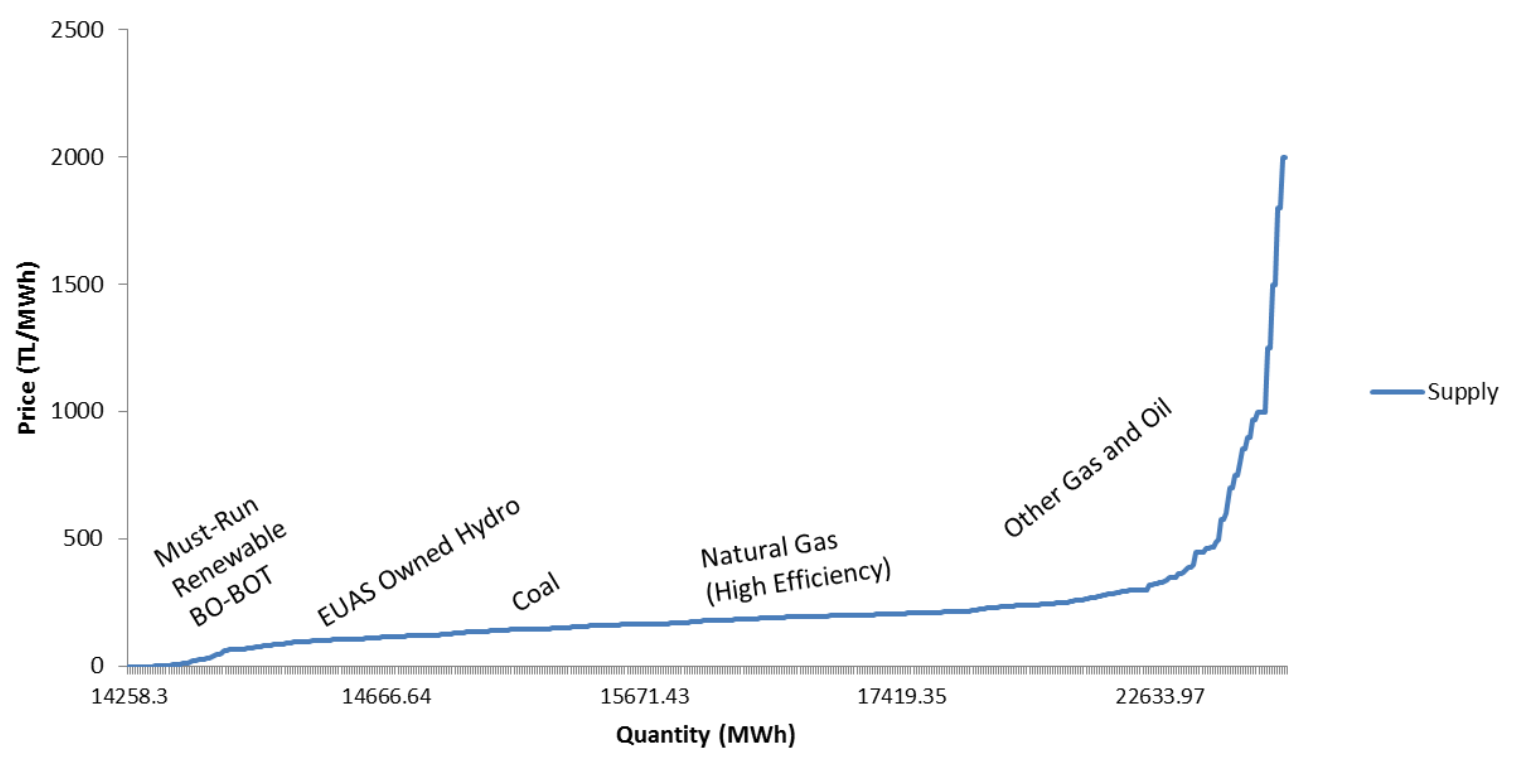

Fig. 2. DAM Merit Order

Source: Energy Exchange Istanbul, EPIAS (2016).

Since the market is shaped on an hourly basis, the equilibrium holds for each hour of the day. Based on this structure, the aggregated hourly supply follows the hourly demand that during night hours, demand is usually low on a given average day and does only require a certain section of the merit order to be fulfilled. On the other hand, during daytime, demand is relatively high and brings more of the merit order into play and causes price fluctuations during the day. Even though there are several drivers that determine price, fundamentally, the price is lower during off-peak hours and is higher during peak hours due to higher supply requirements (higher marginal costs). Similarly, one can expect higher prices for Saturday nights than Wednesday nights due to higher demand; lower prices when wind generation is higher than average; or higher prices when there occurs a problem in natural gas flow.

Table 1. Features of most prominent power plant types in Turkey

\begin{tabular}{|c|c|c|}
\hline $\begin{array}{l}\text { Large-scale hydro (dam) power plant } \\
\text { Generation source: water stream } \\
\text { Ability to store the resource } \\
\text { Ability to schedule dispatch } \\
\text { Influence on prices (decrease) when } \\
\text { generates significant amounts }\end{array}$ & $\begin{array}{l}\text { Small-scale hydro (dam) power plant } \\
\text { Generation source: water stream } \\
\text { Ability to store the resource up to a } \\
\text { certain level } \\
\text { Ability to schedule dispatch }\end{array}$ & $\begin{array}{l}\text { Run-of-river hydro power plant } \\
\text { Generation source: water stream } \\
\text { Must-run generation } \\
\text { Aggregate hydro generation influence prices } \\
\text { (decrease) during wet season }\end{array}$ \\
\hline $\begin{array}{l}\text { Wind energy power plant } \\
\text { Generation source: wind } \\
\text { Must-run generation in zero cost case } \\
\text { Aggregated huge amount of wind } \\
\text { generation may influence the prices } \\
\text { (decrease) }\end{array}$ & $\begin{array}{l}\text { GT or CCGT-natural gas power plant } \\
\text { Generation source: natural gas } \\
\text { Somewhat ability to store the resource } \\
\text { Ability to schedule dispatch } \\
\text { Direct influence on prices (increase) } \\
\text { since price making feature in Turkey } \\
\text { Resource scarcity could be an issue } \\
\text { during extremely cold winters due to } \\
\text { curtailment }\end{array}$ & $\begin{array}{l}\text { Coal power plant } \\
\text { Generation source: hard coal/lignite } \\
\text { Ability to store the resource } \\
\text { Ability to schedule dispatch/normally considered as the } \\
\text { base load/weak flexibility in quick decisions due to } \\
\text { high start-up costs } \\
\text { Semi-direct influence on prices (increase) since one of } \\
\text { the biggest players in supply }\end{array}$ \\
\hline
\end{tabular}

Generators with comparably lower Short-RunMarginal Costs (SRMC), which have negligible impact on price setting bids in the market as price takers, put themselves into infra-marginal category. Thus, for the infra-marginal hydro power plant producer, assuming the marginal cost is very close to zero price, solution to profit maximization shows a price-independent market offer, which only rely on quantity. This highlights the importance of day-ahead price forecasting in 
power markets especially for price-taking power plants, which has storage flexibility. In other words, due to the optionality in the dispatch, price forecasting becomes important.

\section{Methodology: MILP \& SARIMA-ANN Forecasting}

Linear Programming model (LP) is used when problem is faced in a deterministic environment, which is never possible in the energy markets. Hence, there are plenty of assumptions to be defined to receive all the constraint limits and coefficients as a constant. In order to make it more flexible, constraints for capacity usage, "ifthen" or "either-or" expressions are used by modelling the problem with Integer Programming (IP). The main difference is that the variables are discrete and represented either by integer numbers or binaries. Scheduling problems mainly use the mix of LP and IP, which is Mixed Integer Linear Programming (MILP), since time is discrete, but the domain is continuous. The proposed optimization model uses MILP fed by the forecasting results of SANNFORM.

SANNFORM is a hybrid SARIMA-ANN forecasting model that combines the high performance of two distinct forecasting methodologies to successfully explain linear and non-linear components of a data set and to come up with the best fit to have better predictions for the future, and is proposed by Ozozen et al. (2016). The idea of SANNFORM is to first explain the day-ahead prices time series with a SARIMA model that consists of two components such as daily average and hourly profile, then, to apply an Artificial Neural Network (ANN) approach for the error term between real and fit data. When the model is structured, day-ahead price forecast outputs of SARIMA model and error forecasts of ANN model are combined to come up with final day-ahead price forecasts.

\section{Results}

As mentioned in section one, a small-scale hydro power plant owner has the ability to store its water resources up to a certain level, which is limited by its reservoir capacity. Considering the fact that producers have negligible influence upon the price setting, the producer is able to optimize his dispatch schedule subject to foresight of hourly day-ahead market prices and generation constraints, which occurs due to the power plant's technical capabilities and the nature of the generation resource.

Given that the small hydro-plant generator is a price taker (i.e., the price is exogenous), the problem turns into a MILP to seek the right price to generate, considering the producer's storage capacity. In other words, being subjected to capacity constraints, the quantity generated should be shifted durimg the day in order to maximize the profit.

The statement above pushes the producer towards forecasting the prices and water inflows for the dispatch date to come up with an optimized schedule. In this study, the water inflow forecast is provided by the power plant operators and given in MWh, and is used in the optimization problem directly. For the price forecasting side, hybrid SARIMA-ANN model (Ozozen et al., 2016) is used for day-ahead forecasts. Given two inputs, a Mixed Integer Linear Programming model is constructed to optimize the dispatch schedule of the power plant. Fig. 3 below is the simple flowchart of the whole model.

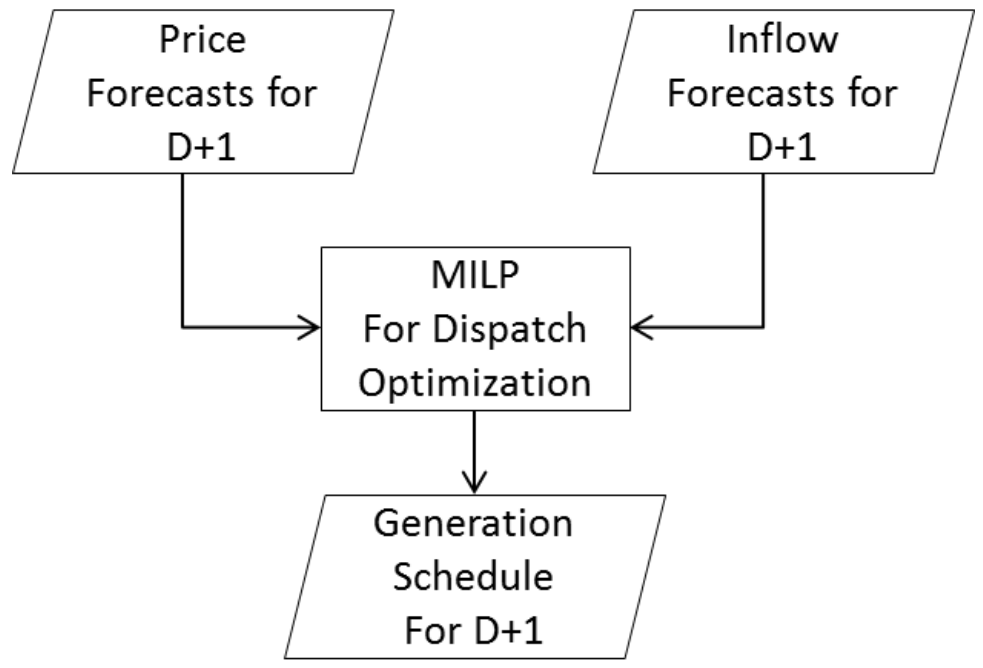

Fig. 3. Dispatch model structure 
3.1. MILP optimization model structure. This section presents the MILP optimization model structure. The objective of the problem is to maximize the profit for the small hydro power plant using the day-ahead price forecasted, which will be higher than the short-run marginal cost considering the capacity and market constraints. The proposed MILP model is designed for hourly schedules at time $t$. The variables and parameters are defined in the following box:

Variables and parameters

$S_{t}$-storage at time $t$

$W S_{t}$-water stream at time $t$

$I_{t}$-water inflow at time $t$

$G_{t}$-generation at time $t$

$x_{t}=\left\{\begin{array}{ll}1 & \text { generation } \\ 0 & \text { otherwise }\end{array}\right\}$

$D A P_{t}$-forecasted value of day-ahead price (TL/MWh) for time $t$

$S R M C$-short-run marginal cost (TL/MWh) of unit generation

Mro -environment-based minimum released output

$K$-storage capacity

$M g$-minimum amount of generation

$T C$-tunnel capacity for turbines

Decision variables are the amount to be generated $G_{t}$, when the generation decision is taken $\left(x_{t}=1\right)$ and the storage amount $S_{t}$ at the reservoir, depending on the water stream $W S_{t}$ and minimum released output Mro related to the inflow $I_{t}$.

Objective is defined as maximizing the profits of power generation for the analyzed small hydro power generator. The generator earns money by the difference of day-ahead price and the short-run marginal cost. If power is generated, the total profit will be total hours of active generation:

$$
\max Z=\sum_{t=1}^{24}\left(D A P_{t}-S R M C\right) * G_{t}^{*} x_{t} .
$$

Constraints: The following limits are to be concerned during the generation of power:

- generation amount is limited to the water inflow and the stored amount:

$$
S_{t+1}-S_{t}-I_{t+1}+G_{t+1} \leq 0 ;
$$

- ecological concern on rivers puts a limit of released output, therefore, the difference of water stream and inflow has to be limited to the minimum released output:

$$
W S_{t}-I_{t}=\text { Mro }
$$

- generated power cannot exceed the stored amount and the inflow:

$$
G_{t}-I_{t}-S_{t-1} \leq 0 ;
$$

- storage is limited by the capacity of the reservoir:

$$
S_{t} \leq K
$$

- generation amount is limited to the tunnel capacity if generation is decided else minimum amount of generation will be the lower limit not to stop the turbines:

$$
\begin{gathered}
M g-G_{t} \leq T C *\left(1-x_{t}\right), \\
G_{t} \leq x_{t} * T C .
\end{gathered}
$$

All the decision variables are real numbers except the decision for generation, which is binary.

$$
\begin{gathered}
x_{t} \in\{0,1\}, \\
G_{t}, S_{t}, W S_{t}, I_{t}, D A P_{t} \in R^{+} .
\end{gathered}
$$

Using all the above definitions, the MILP model can be constructed to solve the equation 1, being subject to equations 2 to 9 .

\subsection{Dispatch scheduling based on DAP forecasts.} The authors use four different methodologies for the above optimization problem in order to evaluate the success rate of proposed hybrid price forecasting model. Based on these methodologies, four different dispatch schedules are discussed. Below, the dispatch schedules are given with corresponding conditions.

Proposed schedule: Dispatch based on optimization model using SANNFORM forecasted as exogenous price inputs.

Schedule 2: Dispatch based on optimization model using previous day's same hour prices as exogenous price inputs.

Schedule 3: Dispatch decision is taken when storage level is greater equal than $\mathrm{Mg}$ with $\mathrm{Mg}$ 
amount of generation.

Schedule 4: Dispatch decision is taken when storage is at full capacity with half-storage amount of generation.

For each one of the methodologies, the problem is solved for 3 consecutive days and the results are discussed for several aspects.

3.3. Case implementation for stand-alone HEPP owner. The study is held for a small-scale hydro power plant to discuss the aforementioned four different schedule scenarios for their outputs and to decide upon the best possible dispatch schedule. Due to the geographical and meteorological nature of the power plant's location, water inflow to the dam, which is the main resource for power plant's generation, follows a varying yearly profile. Water level starts increasing as soon as melting season starts and follows a flat profile during the wet season. Followed by a transition season, which occurs due to decreasing melting and rainfall seasonality, dry season comes into play. It is the time where melting has almost no effect and snow starts gathering around dam and waterbed.

In order to show the most reliable effects of dispatch optimization for a stand-alone smallscale hydro power plant, test days are selected from dry season for the generation source is the scarcest during dry season.

The properties, which are discussed throughout the MILP model for the hydro power plant, are given in Table 2 below.

Table 2. Hydro power plant's technical properties

\begin{tabular}{|l|c|}
\hline Capacity of the reservoir (K) & $48.82 \mathrm{MW}$ \\
\hline Tunnel capacity (TC) & $70.05 \mathrm{MW}$ \\
\hline Minimum released output (Mro) & $0.1 \mathrm{MWh}$ \\
\hline Minimum generation condition (Mg) & $5 \mathrm{MWh}$ \\
\hline Short-run marginal cost (SRMC) & $0 \mathrm{TL} / \mathrm{MWh}$ \\
\hline
\end{tabular}

Note: *0.1 MWh equals to $0.150 \mathrm{~m}^{3} / \mathrm{sn}$ water inflow for the corresponding efficiency level and dam's properties. **SRMC is considered to be zero due to renewable advantage. Long-run costs and how they are affected by the optimization results are discussed in subsection 3.4 .

The water inflow quantity $\left(I_{t}\right)$ is given as the smart meters stationed along the waterbed and exogenous inputs for the model and provided by is taken in the given units as exogenous input in the power plant as forecasted. In addition, the the model. The inflow to the dam is given in the inflow is easily measured in MWh units thanks to graph below.

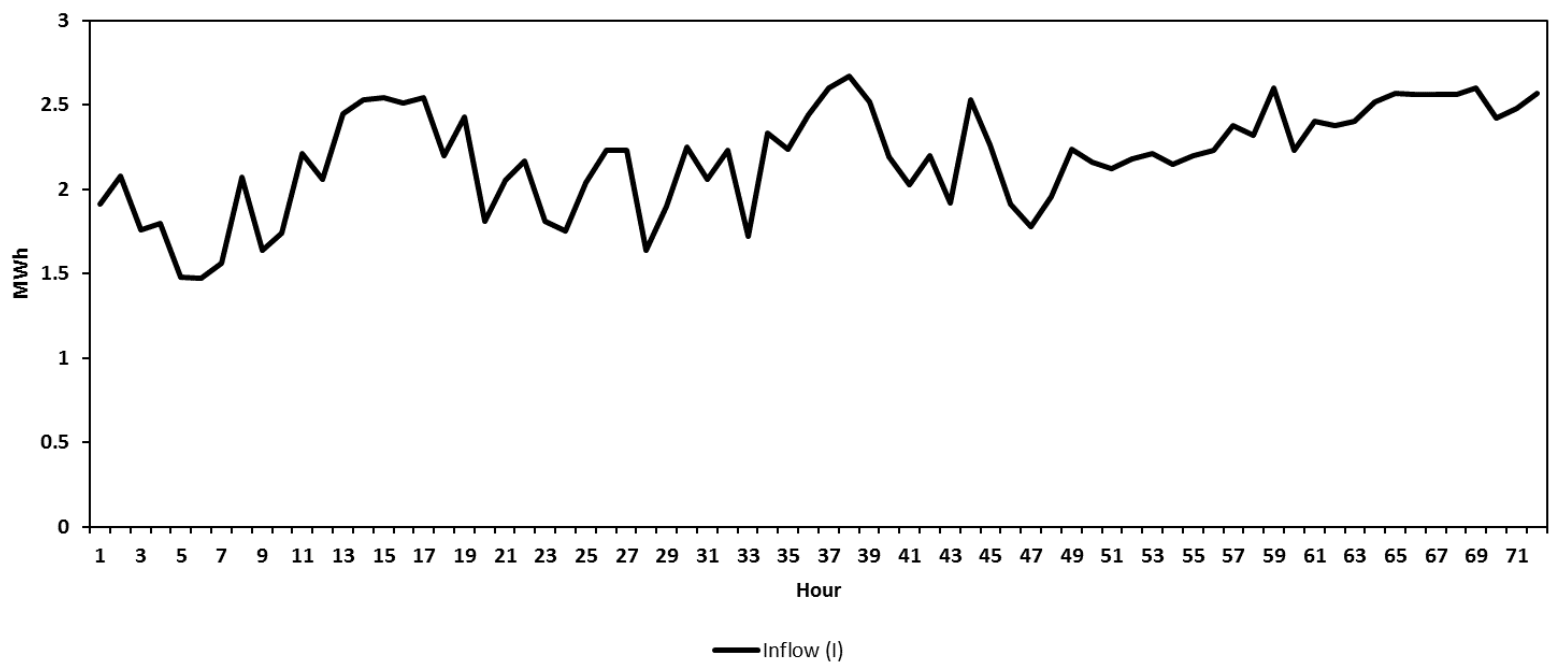

Fig. 4. Water inflow forecasts (after Mro is deducted) for the given period

The case is studied and the results for the period between 05/12/16 - 07/12/16 are shared.

3.4. Outcomes and discussions. Price forecasting performance: day-ahead market prices are forecasted for the planning period using the hybrid SANNFORM methodology. The results with performance indicators are given below. 
Price Forecasting Performance

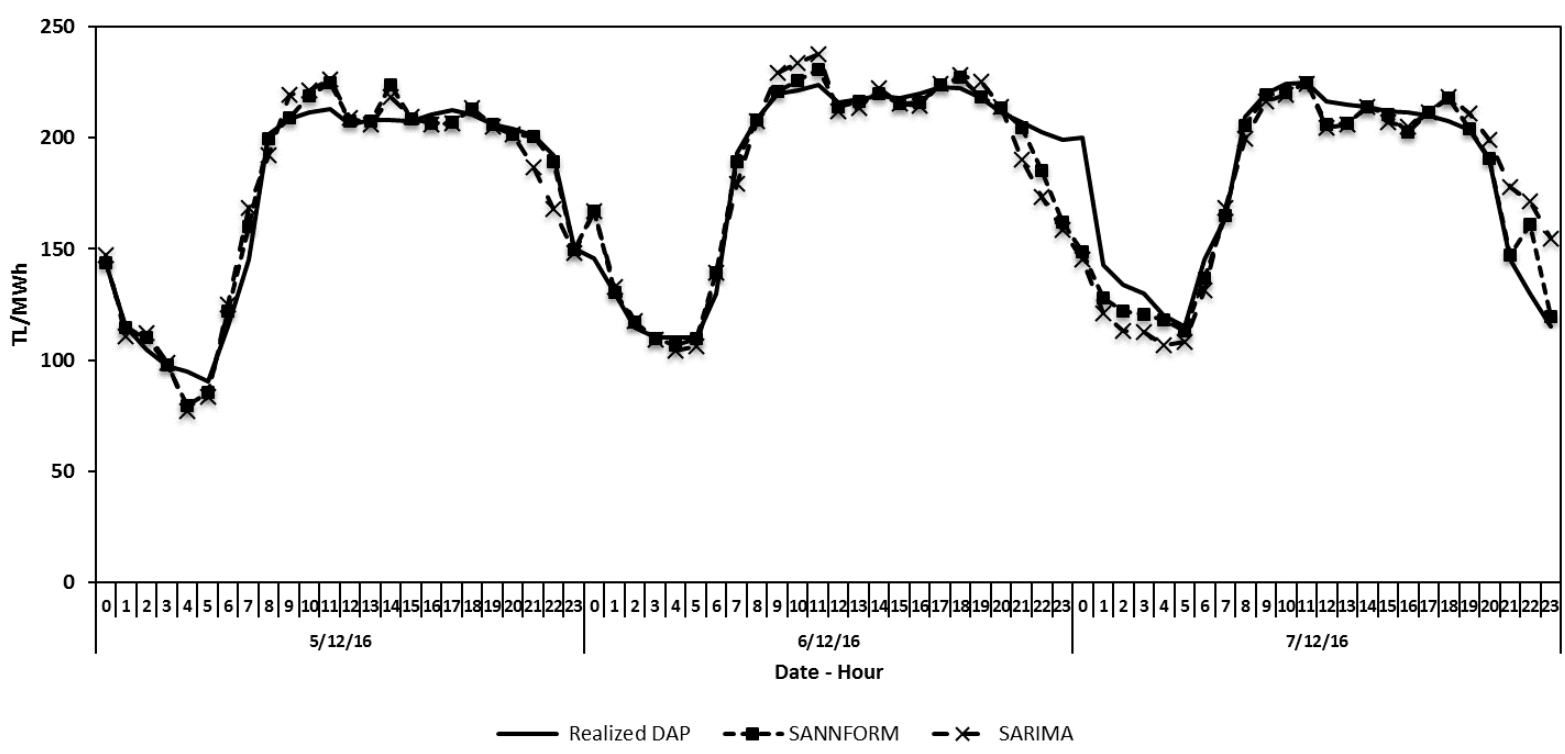

Fig. 5. Day-ahead price forecasting results for the studied period

Table 3. Price forecasting model's performance

\begin{tabular}{|l|c|}
\hline \multicolumn{1}{|c|}{ Forecasting model } & MAPE \\
\hline SANNFORM $^{*}$ & $3.6 \%$ \\
\hline SARIMA $^{*}$ & $6.5 \%$ \\
\hline
\end{tabular}

Note: *Both models are constructed and evaluated as discussed in SANNFORM.

Given in Table 3 above, hybrid SARIMA-ANN model gives better results in terms of meanabsolute percentage error (MAPE). Hence, SANNFORM forecasting results are used for the
MILP model as exogenous price inputs. MILP Performance: 4 different dispatch schedules are studied for the case as discussed under 5.2. And the results are given in Table 4 below.

Table 4. Case results for 4 different dispatch schedules

\begin{tabular}{|l|c|c|c|c|}
\hline & Proposed schedule & Schedule 2 & Schedule 3 & Schedule 4 \\
\hline $\begin{array}{l}\text { Total revenue } \\
(\mathrm{TL})\end{array}$ & $33,838.29$ & $32,924.48$ & $28,751.95$ & $22,013.43$ \\
\hline $\begin{array}{l}\text { Total generation } \\
\text { (MWh) }\end{array}$ & 162.04 & 164.61 & 155.00 & 122.05 \\
\hline $\begin{array}{l}\text { Revenue margin } \\
\text { (TL/MWh) }\end{array}$ & 208.83 & 200.02 & 185.50 & 180.36 \\
\hline $\begin{array}{l}\text { End storage } \\
\text { (MWh) }\end{array}$ & 7.68 & 5.11 & 14.72 & 47.67 \\
\hline Number of dispatch hours & 12 & 17 & 31 & 5 \\
\hline MWh/Dispatch & 13.5 & 9.7 & 5.0 & 24.4 \\
\hline $\begin{array}{l}\text { Storage value* } \\
\text { (TL) }\end{array}$ & $1,375.56$ & 915.25 & $2,636.48$ & $8,538.11$ \\
\hline $\begin{array}{l}\text { Revenue margin-I** } \\
\text { (TL/MWh) }\end{array}$ & 207.48 & 199.39 & 184.94 & 180.01 \\
\hline
\end{tabular}

Note: *The end storage volume at the end of the day is multiplied by the average DAP of the operation day. **Revenue margin-II is calculated to include end storage value to the revenue margin. Storage value is added to revenue and then the total is divided by (generation + end storage volume).

As can be clearly seen from the table above, the best performance in terms of revenue margin is measured for the proposed schedule. The performance improvements between schedules are given in Table 5 below. 
Table 5. Performance improvements

\begin{tabular}{|c|c|c|c|c|}
\hline & Proposed schedule & Schedule 2 & Schedule 3 & Schedule 4 \\
\hline Proposed schedule & - & $4.1 \%$ & $12.2 \%$ & $15.3 \%$ \\
\hline Schedule 2 & - & - & $7.8 \%$ & $10.8 \%$ \\
\hline Schedule 3 & - & - & - & $2.7 \%$ \\
\hline Schedule 4 & - & - & - & - \\
\hline
\end{tabular}

Storage levels and the generation amounts for the proposed dispatch schedule are given below in Figures 6 and 7 with corresponding DAPs.

\section{Dispatch Schedule}

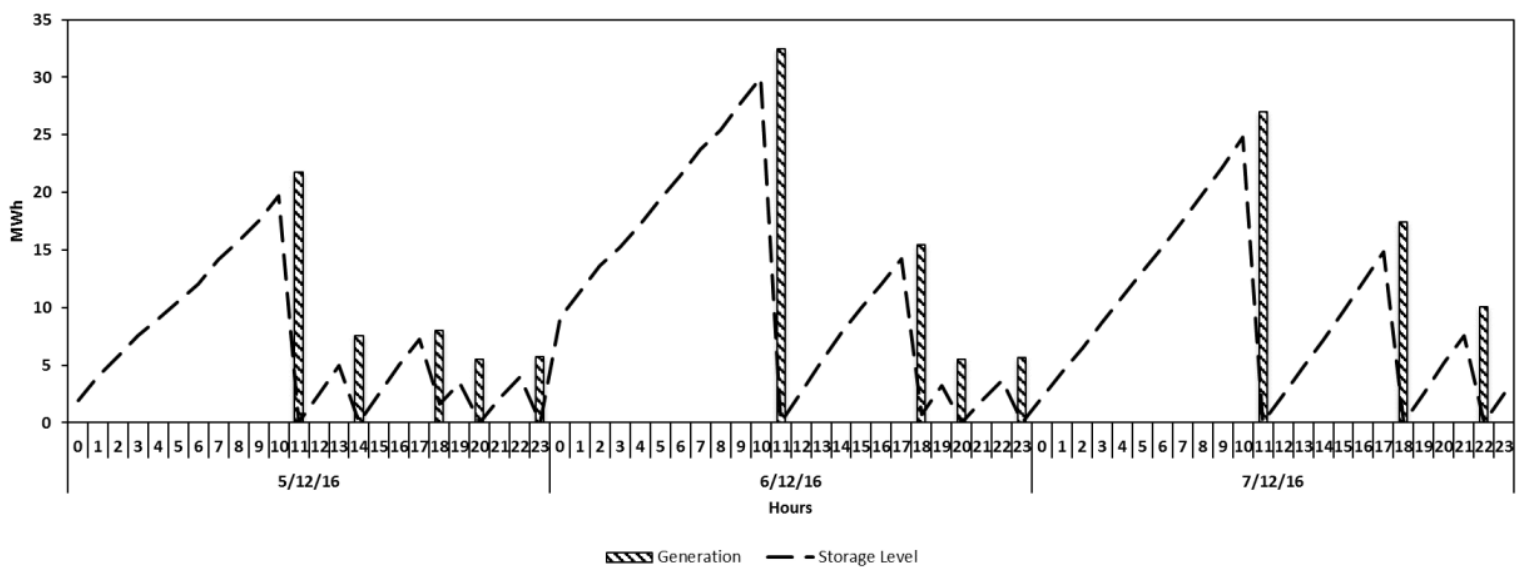

Fig. 6. Optimized dispatch schedule for the given period

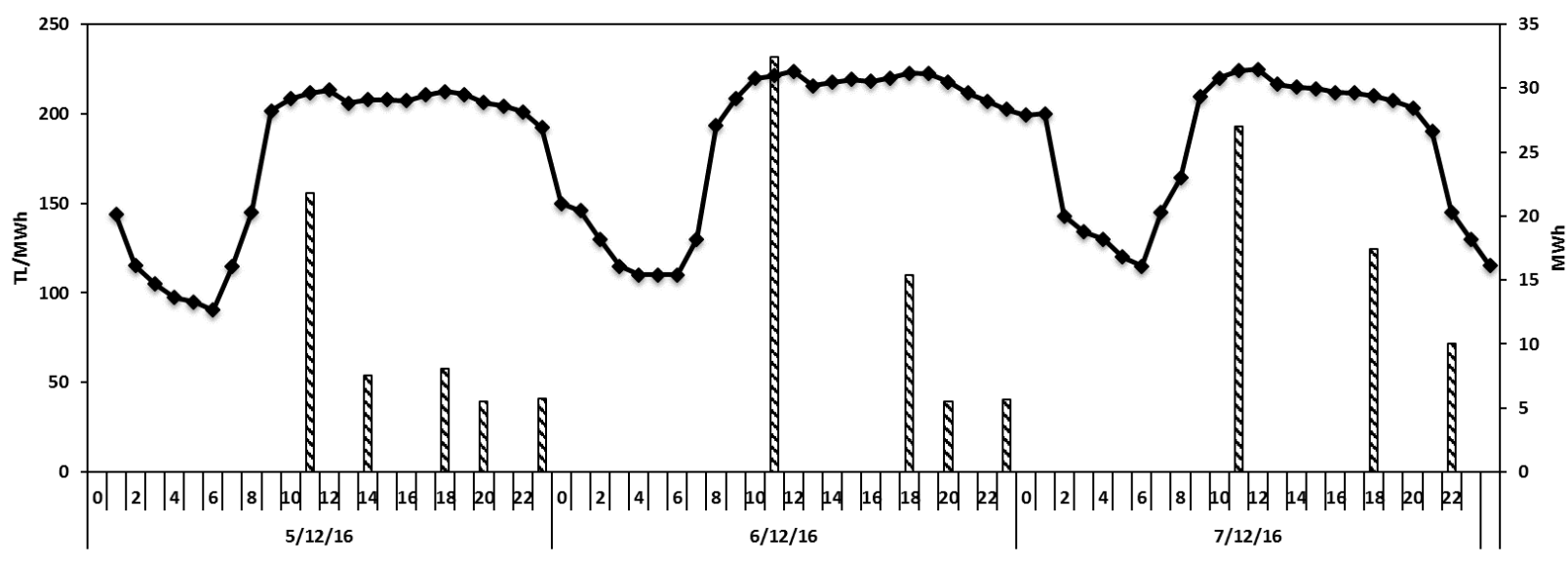

$\rightarrow$ DAP

Fig. 7. Optimized dispatch schedule compared with realized day-ahead prices

As clearly seen from the above picture, thanks to the excellent performance of price forecasting model, MILP optimization came up with the best possible dispatch schedule. Since the prices were successfully forecasted, proposed schedule gives the dispatch order for the times when the prices are comparably high. This is why dispatch is done during peak hours almost without exception. In brief, somewhat flexible nature of hydro power plant power generation and accurate price forecasting results in maximized revenue gain with the correct dispatch optimization.

An optimized dispatch schedule results in:
- higher revenue margin;

- higher efficiency (as a result, reduced long-run costs);

- reliable and non-variable renewable generation during peak hours.

\section{Conclusion and recommendations}

As the degree of liberalization increases in the energy sector, it becomes more and more complex and becomes part of a more linked network. More complexity is introduced due to the uncertainties caused by renewable energy generators. While the 
large-sized natural gas power plants, the nuclear plants or the hydro power generators have market power and are effective in the market price establishment, the small-sized hydro power plants and wind power plant owners individually have almost no effect.

This study analyzes the profit maximizing policies of the suppliers with less market power. The authors suggest a model to optimize the stop/store/start decisions based on a market price forecast performed using a new SARIMA-ANN forecasting method. Using a Mixed Integer Linear Programming for a small-sized hydro-plant, it is showed that changing the policies on the right time with the good forecasts can maximize the profit of a small player.

In order to maximize its profits, policies for a small hydro-plant generator are suggested based on an optimum schedule of three days. The MILP model designed for optimization uses the day-ahead market price forecasts, resulted running a hybrid SARIMA-ANN price forecasting methodology. The case application in Turkish power market shows the increase of profit with a reliable generation schedule. The best performance in terms of revenue margin is measured for the proposed schedule.

The performance of price forecasting model resulted with the best possible dispatch schedule. Since the prices were successfully forecasted, proposed schedule gives the dispatch order for the times when the prices are comparably high. This is why dispatch is done during peak hours almost without exception. In brief, somewhat flexible nature of hydro power plant power generation and accurate price forecasting results in maximized profit gain with the correct dispatch optimization.

The optimized dispatch schedule proposed here leads to higher profit margin; higher efficiency and hence, as a result, reduced long-run marginal costs and, finally, reliable and non-variable renewable generation during peak hours.

\section{References}

1. Braun, S. (2016). Hydropower Storage Optimization Considering Spot and Intraday Auction Market. Energy Procedia, 87, 36-44. https://doi.org/10.1016/j.egypro.2015.12.355

2. Contreras, J., Candiles, O., de la Fuente, J. I., \& Gómez, T. (2001). Auction Design in Day-Ahead Electricity Markets (Republished). IEEE Transactions on Power Systems, 16(3), 409-417.

3. Efthymoglou, P. G., \& Vlachou, A. S. (1989). Productivity in the Vertically Integrated System of the Greek Electricity Utility. Energy Economics, 11(2), 119-126. Retrieved from http://www.sciencedirect.com/science/article/pii/0140988389900042 (accessed on February 22, 2015).

4. Fazlollahi, S., Mandel, P., Becker, G., \& Marechal, F. (2012). Methods for Multi-Objective Investment and Operating Optimization of Complex Energy Systems. Energy, 45, 12-22.

5. Gabriel, S. A., Conejo, A. J., Fuller, J. D., Hobbs, B. F., \& Ruiz, C. (2013). International Series in Operations Research \& Management Science: 180 Complementarity Modeling in Energy Markets. https://doi.org/10.1007/978-1-4419-6123-5

6. Gangammanavar, H., Sen, S., \& Zavala, V. M. (2016). Stochastic Optimization of Sub-Hourly Economic Dispatch with Wind Energy. IEEE Transactions on Power Systems, 31(2), 949-959.

7. Harris, C. (2013). Electricity Markets: Pricing, Structures and Economics.

8. Kekatos, V., Veeramachaneni, S., Light, M., \& Giannakis, G. B. (2013). Day-Ahead Electricity Market Forecasting Using Kernels. Paper presented at 2013 IEEE PES Innovative Smart Grid Technologies Conference, ISGT 2013.

9. Keles, D., Scelle, J., Paraschiv, F., \& Fichtner, W. (2016). Extended Forecast Methods for Day-Ahead Electricity Spot Prices Applying Artificial Neural Networks. Applied Energy, 162, 218-230.

10. Mandal, P., ul Haque, A., Meng, J., Srivastava, A. K., \& Martinez, R. (2013). A Novel Hybrid Approach Using Wavelet, Firefly Algorithm, and Fuzzy ARTMAP for Day-Ahead Electricity Price Forecasting. IEEE Transactions on Power Systems, 28(2), 1041-1051. https://doi.org/10.1109/TPWRS.2012.2222452

11. Marzband, M., Sumper, A., Ruiz-Alvarez, A., Dominguez-Garcia, J. L., \& Tomoiaga, B. (2013). Experimental Evaluation of a Real Time Energy Management System for Stand-Alone Microgrids in Day-Ahead Markets. Applied Energy, 106, 365-376. https://doi.org/10.1016/j.apenergy.2013.02.018

12. Ozozen, A., Kayakutlu, G., Ketterer, M., \& Kayalica, M. Ö. (2016). A Combined Seasonal ARIMA and ANN Model for Improved Results in Electricity Spot Price Forecasting: Case Study in Turkey. 2016 Proceedings of PICMET'16: Technology Management for Social Innovation. Honolulu, Hawaii, USA.

13. Panapakidis, I. P., \& Dagoumas, A. S. (2016). Day-Ahead Electricity Price Forecasting via the Application of Artificial Neural Network Based Models. Applied Energy, 172, 132-151.

14. Pousinho, H. M. I., Esteves, J., Mendes, V. M. F, Collares-Pereira, M., \& Pereira Cabrita, C. (2016). Bilevel Approach to Wind-CSP Day-Ahead Scheduling with Spinning Reserve under Controllable Degree of Trust. Renewable Energy, 85, 917-927. https://doi.org/10.1016/j.renene.2015.07.022 
15. Samimi, A., Kazemi, A., \& Siano, P. (2015). Economic-Environmental Active and Reactive Power Scheduling of Modern Distribution Systems in Presence of Wind Generations: A Distribution Market-Based Approach. Energy Conversion and Management, 106, 495-509.

16. Shayegan-Rad, A., Badri, A., \& Zangeneh, A. (2017). Day-Ahead Scheduling of Virtual Power Plant in Joint Energy and Regulation Reserve Markets under Uncertainties. Energy, 121, 114-125.

17. Wang, X., Jiang, C., \& Li, B. (2016). Active Robust Optimization for Wind Integrated Power System Economic Dispatch Considering Hourly Demand Response. Renewable Energy, 97, 798-808.

18. Yan, X., Abbes, D., \& Francois, B. (2017). Uncertainty Analysis for Day Ahead Power Reserve Quantification in an Urban Microgrid Including PV Generators. Renewable Energy, 106, 288-297.

19. Zamani, A. G., Zakariazadeh, A., Jadid, S., \& Kazemi, A. (2016). Stochastic Operational Scheduling of Distributed Energy Resources in a Large Scale Virtual Power Plant. International Journal of Electrical Power \& Energy Systems, 82, 608-620.

20. Ziel, F., Steinert, R., \& Husmann, S. (2015). Forecasting Day Ahead Electricity Spot Prices: The Impact of the EXAA to Other European Electricity Markets. Energy Economics, 51, 430-444. 